\title{
Addressing a clinical challenge: guidelines for the diagnosis and treatment of leishmaniasis
}

\author{
Naomi E. Aronson
}

\begin{abstract}
Leishmaniasis is a chronic intracellular parasitic infection that travelers, immigrants, deployed military personnel, and refugees from endemic global areas acquire from the bite of infected sand flies and carry with them, including to non-endemic countries where leishmaniasis may be an unfamiliar illness to medical providers. This commentary discusses the first clinical practice guidelines produced by the Infectious Diseases Society of America and American Society of Tropical Medicine and Hygiene for the diagnosis and management of leishmaniasis, targeted for clinicians in North America.
\end{abstract}

Keywords: Leishmaniasis, Clinical practice guidelines, Diagnosis, Treatment

\section{Background}

Leishmaniasis, caused by various Leishmania parasites and transmitted by the bite of an infected sand fly vector, is on the rise [1]. An immunologically unprotected host who travels to any of the 88 countries with areas of endemic leishmaniasis is at risk of acquiring infection. Whether the inciting event be population displacement due to conflict or food insecurity, refugee relocation, ecotourism, urbanization, or northward extension of the sand fly vector with global warming trends, the end result is that more patients with cases of leishmaniasis will present to healthcare systems in non-endemic Europe and North America. Some countries (e.g., India, Bangladesh, Nepal) are working toward eliminating visceral leishmaniasis (VL); however, VL epidemics occur in Sudan and South Sudan, and there are increased rates of VL cases in Brazil as a result of populations moving from rural to densely populated peri-urban regions. Recent epidemics of cutaneous leishmaniasis $(\mathrm{CL})$ have been associated with an earthquake in Bam, Islamic Republic of Iran; with refugees and displaced persons in Kabul, Afghanistan; with the US military operations in Operation Iraqi Freedom 2003-2005; and as a consequence of the conflict in Syria.

Correspondence: naomi.aronson@usuhs.edu

Division of Infectious Diseases, Uniformed Services University of the Health Sciences, 4301 Jones Bridge Road, Bethesda, MD 20814, USA
The United Nations High Commissioner for Refugees reported that 65 million persons were displaced in 2015 and that three countries provided one half of the worlds' refugees: Syria, Afghanistan, and Somalia [2]. In two of these countries, Syria and Afghanistan, leishmaniasis is endemic. The visible signs of CL (chronic skin sores often on exposed parts of the body) broadcast an obvious indication of emerging infection in unprotected populations. While the Syrian Ministry of Health reported a twofold increase in CL cases in 2013, some feel the number of CL cases could exceed 100,000 per year [3]. In a GeoSentinel surveillance study, $32 \%$ of adult Syrian refugees evaluated for migration-related illness had CL [4]. Increased CL rates were also reported in the neighboring countries of Jordan [5], Lebanon [6, 7], and Turkey [8,9], primarily among Syrian refugee populations. Poor living conditions, disrupted healthcare infrastructure, vector control programs, inadequate sanitation, and mass migration from non-endemic regions of Syria through endemic areas all likely contribute to an increased disease burden of leishmaniasis in Syrian refugees.

An additional contributor to the rise of VL is decreased host susceptibility. Globally, this is most commonly caused by malnutrition, but in high-resourced countries this can also be caused by immunosuppression. Causative factors for the latter include HIV-Leishmania co-infection, initially recognized in Mediterranean intravenous drug users 
but now seen worldwide, and risks associated with biologic immunomodulating drugs, including post transplantation, and with the burgeoning use of tumor necrosis factoralpha inhibitors $[10,11]$.

\section{Discussion}

In 2007, the World Health Assembly passed a resolution on the control of leishmaniasis, raising awareness of these infections [12]. Subsequently, several major clinical guidelines have been published, but they were not targeted toward clinical management in North America [13]. In the USA, there is a dichotomous dilemma with the diagnosis and care of patients with leishmaniasis. Healthcare is well resourced, but leishmaniasis is not endemic and most providers may not recognize the typical signs and symptoms. Aside from histopathology, diagnostic testing is relegated to a few reference laboratories only. Most drugs used globally to treat leishmaniasis are not approved by the Food and Drug Administration for use in the USA and may not be easily available. In light of these challenges, detailed clinical practice guidelines for the diagnosis and management of leishmaniasis in North America were recently published $[14,15]$ after an inaugural collaboration between the Infectious Diseases Society of America (IDSA) and the American Society of Tropical Medicine and Hygiene (ASTMH).

The IDSA-ASTMH leishmaniasis clinical practice guidelines were structured by including questions that commonly arise in clinical practice. They provide practical tables, maps of endemic areas, clinical photographs, and contact details for reference diagnostic laboratories. These guidelines are detailed; they are organized into nine diagnostic questions (22 recommendations) and 26 treatment questions (57 recommendations) covering $\mathrm{CL}$, mucosal leishmaniasis (ML), VL, and leishmaniasis management in the immunocompromised host and in special populations (young children, elderly persons, women who are pregnant or lactating, and persons with medical comorbidities). Only the executive summary is published in paper format, but each question has an associated evidence summary available online. The guidelines are extensively referenced ( $>500$ references) and a supplemental appendix has a searchable document of controlled CL treatment trials, transparently allowing a provider to assess the quality of evidence, and allowing them to search by country of acquisition, Leishmania species, and type/route of treatment. Many of the guideline recommendations derive from observational trials and case reports, or consist of expert opinion. Recommendations are given based on a determination of the strength of the recommendation (strong or weak) and the quality of evidence (high, moderate, low, very low). In the guidelines, $14 \%$ of the diagnostic recommendations and $16 \%$ of the therapeutic recommendations were rated as weak; with regards the quality of evidence, diagnostic (32\% moderate, $48 \%$ low, $19 \%$ very low) and therapeutic (4\% high, $20 \%$ moderate, $49 \%$ low, and $27 \%$ very low) recommendations were skewed to lower-quality studies.

In the context of a majority of low/very low quality of evidence, applying GRADE (grading of recommendations, assessment, development, and evidence) methodology is challenging. Early on, the committee decided to address questions for clinicians, whether or not the published evidence was adequate. The guidelines took in excess of 5 years to complete and are lengthy as well as complex. For the North American audience, new areas of focus include managing immunocompromised hosts (not just HIV) and special populations, and a discussion of the new drug, miltefosine, and its current role in treatment. Local therapies are reviewed for treating uncomplicated leishmaniasis, such as Old World CL; these approaches have been underutilized in the USA. Some of the more controversial recommendations among the group included whether to refer patients with Viannia subgenus infection for expert otolaryngological examination regardless of symptoms (the chosen recommendation was that these patients should be referred). Another controversial topic was whether determining the Leishmania species responsible for the infection (requiring culture or reference laboratory support) is informative enough to make it worthwhile in most cases (again, the answer was yes). The use of serology alone (rK39) for the diagnosis of VL was discouraged, with the recommendations advocating for parasitic confirmation. The sole recommendation for which consensus was not reached was whether New World CL north of Costa Rica could be managed by observation without intervention-if healing on its own-because it is geographically thought to have less risk of metastasizing to cause $\mathrm{ML}$; one member with a great deal of ML experience felt that all should receive treatment.

Preparing these leishmaniasis guidelines often led to more questions than answers. One area ripe for additional research is the management of leishmaniasis in the non-HIV immunocompromised host (e.g., post transplant or being treated with biologic immunomodulating drugs). In general, this neglected tropical disease requires fully powered sample sizes in well-done comparative clinical trials with standardized outcome measures to develop a stronger evidence base. This will likely require the collaboration of consortia across regions to refine the best treatment approaches. Until this evidence is available, the guidelines generally define simple and complicated $\mathrm{CL}$ as the initial decision node for local versus systemic treatment, but emphasize that treatment choice should be individualized; there is no universally applicable treatment dose, route of administration, drug, or duration of therapy. 


\section{Conclusions}

The IDSA-ASTMH clinical practice guidelines provide a sensible current approach for clinicians evaluating and treating patients with leishmaniasis. We aimed to give clear recommendations from evidence that was often inadequate, but drawing upon our collective clinical expertise in managing leishmaniasis. More leishmaniasis cases are now seen in adventurous travelers, immigrants, refugees, and military personnel. These guidelines serve as a definitive reference to assist with the management of this clinically challenging infection. Lastly, the notable absence of an effective vaccine for leishmaniasis or prophylactic treatment highlights that prevention is essential to stopping the global rise of leishmaniasis.

\section{Abbreviations}

ASTMH: American Society of Tropical Medicine and Hygiene; CL: Cutaneous leishmaniasis; GRADE: Grading of recommendations, assessment, development, and evidence; HIV: Human immunodeficiency virus; IDSA: Infectious Diseases Society of America; ML: Mucosal leishmaniasis; VL: Visceral leishmaniasis

\section{Acknowledgements}

Author disclaimer: The views, information, content, and conclusions expressed herein are those of the author and do not reflect the official position or policy of the Departments of Defense, or any other agency of the U.S. Government, nor should any official endorsement be inferred by the Department of Defense, or the U.S. Government.

\section{Competing interests}

The author declares that she has no competing interests.

\section{Publisher's Note}

Springer Nature remains neutral with regard to jurisdictional claims in published maps and institutional affiliations.

Received: 13 March 2017 Accepted: 23 March 2017

Published online: 07 April 2017

\section{References}

1. Desjeux P. The increase in risk factors for leishmaniasis worldwide. Trans $R$ Soc Trop Med Hyg. 2001;95(3):239-43.

2. Global Trends 2015 [http://www.unhcr.org/en-us/global-trends-2015.html]. Accessed 27 Mar 2017.

3. Du R, Hotez PJ, Al-Salem WS, Acosta-Serrano A. Old World Cutaneous Leishmaniasis and Refugee Crises in the Middle East and North Africa. PLoS Negl Trop Dis. 2016;10(5):e0004545.

4. FP Mockenhaupt, Barbre KA, M Jensenius, CS Larsen, ED Barnett, W Stauffer, C Rothe, H Asgeirsson, DH Hamer, DH Esposito, P Gautret, P Schlagenhauf. Profile of illness in Syrian refugees: a geosentinel analysis, 2013 to 2015. Eurosurveillance. 2016;21(10):30160. doi:10.2807/1560-7917.ES.2016.21.10. 30160.

5. His E, Murshidi MM, Hijjawi MQ, Jeriesat S, Eltom A. Syrian refugees and Jordan's health sector. Lancet. 2013:382(9888):206-7.

6. Alawieh A, Musharrafieh U, Jaber A, Berry A, Ghosn N, Bizri AR. Revisiting leishmaniasis in the time of war: the Syrian conflict and the Lebanese outbreak. Int J Infect Dis. 2014;29:115-9.

7. Saroufim M, Charafeddine K, Issa G, Khalifeh H, Habib RH, Berry A, Ghosn N, Rady A, Khalifeh I. Ongoing epidemic of cutaneous leishmaniasis among Syrian refugees, Lebanon. Emerg Infect Dis. 2014;20(10):1712-5.

8. Ozkeklikci A, Karakus M, Ozbel Y, Toz S. The new situation of cutaneous leishmaniasis after Syrian civil war in Gaziantep city, Southeastern region of Turkey. Acta Trop. 2017;166:35-8.

9. Inci R, Ozturk P, Mulayim MK, Ozyurt K, Alatas ET, Inci MF. Effect of the Syrian civil war on prevalence of cutaneous leishmaniasis in Southeastern Anatolia, Turkey. Med Sci Monit. 2015;21:2100-4.
10. Neumayr AL, Morizot G, Visser LG, Lockwood DN, Beck BR, Schneider S, Bellaud G, Cordoliani F, Foulet F, Laffitte EA, et al. Clinical aspects and management of cutaneous leishmaniasis in rheumatoid patients treated with TNF-alpha antagonists. Travel Med Infect Dis. 2013;11(6):412-20.

11. van Griensven J, Carrillo E, Lopez-Velez R, Lynen L, Moreno J. Leishmaniasis in immunosuppressed individuals. Clin Microbiol Infect. 2014;20(4):286-99.

12. World Health Organization. Leishmaniasis in high-burden countries: an epidemiological update based on data reported in 2014. Releve epidemiologique hebdomadaire. 2016;91(22):287-296.

13. Copeland NK, Aronson NE. Leishmaniasis: treatment updates and clinical practice guidelines review. Curr Opin Infect Dis. 2015;28(5):426-37.

14. Aronson N, Herwaldt BL, Libman M, Pearson R, Lopez-Velez R, Weina P, Carvalho E, Ephros M, Jeronimo S, Magill A. Diagnosis and treatment of leishmaniasis: clinical practice guidelines by the Infectious Diseases Society of America (IDSA) and the American Society of Tropical Medicine and Hygiene (ASTMH). Am J Trop Med Hyg. 2017;96(1):24-45.

15. Aronson N, Herwaldt BL, Libman M, Pearson R, Lopez-Velez R, Weina P, Carvalho EM, Ephros M, Jeronimo S, Magill A. Diagnosis and treatment of leishmaniasis: clinical practice guidelines by the Infectious Diseases Society of America (IDSA) and the American Society of Tropical Medicine and Hygiene (ASTMH). Clin Infect Dis. 2016;63(12):e202-64.

Submit your next manuscript to BioMed Central and we will help you at every step:

- We accept pre-submission inquiries

- Our selector tool helps you to find the most relevant journal

- We provide round the clock customer support

- Convenient online submission

- Thorough peer review

- Inclusion in PubMed and all major indexing services

- Maximum visibility for your research

Submit your manuscript at www.biomedcentral.com/submit
) Biomed Central 